\title{
“You're never making just one decision": Exploring the lived experiences of ambulance Emergency Operations Centre personnel
}

Astrid Coxon ${ }^{1}$, Mark Cropley ${ }^{2}$; Pat Schofield ${ }^{3}$; Kath Start ${ }^{4,5}$; Claire Horsfield, ${ }^{4,5}$ Tom Quinn,6

${ }^{1}$ Faculty of Medicine and Health Sciences, University of East Anglia, UK

${ }^{2}$ School of Psychology, Faculty of Health and Medical Sciences, University of Surrey, Guildford, UK

${ }^{3}$ Faculty of Health, Social Care and Education, Anglia Ruskin University, Chelmsford, UK.

${ }^{4}$ School of Health Sciences, Faculty of Health and Medical Sciences, University of Surrey, Guildford UK

${ }^{5}$ South East Coast Ambulance NHS Foundation Trust, Banstead, Surrey, UK

${ }^{6}$ Faculty of Health, Social Care and Education, Kingston University and St George’s, University of London, London, UK

Word count: 7159

Corresponding author: Dr Mark Cropley, Professor, School of Psychology, Faculty of Health and Medical Sciences, University of Surrey, Guildford, GU2 7XH, UK;

mark.cropley@surrey.ac.uk 


\begin{abstract}
Background The aim of this study was to explore the experiences of ambulance dispatch personnel, identifying key stressors and their impact on staff wellbeing.

Methods Qualitative methodology was used. Nine semi-structured interviews were conducted with NHS ambulance Emergency Operations Centre (EOC) dispatch personnel in the UK between July and August 2014. Participants were asked about their experiences of the role, stress experienced, and current strategies they use to deal with stress. Transcripts were analysed using an inductive, bottom-up thematic analysis.
\end{abstract}

Results Three key themes were identified: (1) 'How dispatch is perceived by others', (2) 'What dispatch really involves' and (3)’Dealing with the stresses of dispatch'. All participants expressed pride in their work but felt overloaded by the workload and undervalued by others. Several sources of additional stress, not directly related to the execution of their work, were identified, including the need to mentally unwind from work at the end of a shift. Participants were able to identify a number of ways in which they currently manage work-related stress, but they also suggested changes the organisation could put in place in order to reduce stress in the working environment.

Conclusions Building on existing theory on work stress and post-work recovery, it was concluded that EOC dispatch staff require greater support at work, including skills training to 
promote post-shift recovery, in order to reduce the likelihood of sickness absence, and prevent work-related fatigue.

\section{What this paper adds}

What is already known on this subject?

Prior research examining the stressors experienced by call operatives has been conducted but to date the experience of working as emergency medical services (EMS) dispatch personnel remain under-researched. Moreover, the role of the ambulance dispatcher has been largely overlooked in academic research.

Without a clearer understanding of the unique experiences of EMS dispatchers, it is difficult to offer advice on how best to improve and promote wellbeing, and ultimately reduce sickness absence and staff turnover within this group.

\section{What might this study add?}

Using qualitative interviews our study identified a number of extra- and intra-personal stressors Emergency Operations Centre dispatch personnel experience, falling into three broad categories: resources and pay, interpersonal difficulties, and feeling overworked and undervalued.

\section{INTRODUCTION}

The Emergency Operations Centre (EOC) is the first point of contact between the public and emergency medical services (EMS) in an emergency, and EOC personnel face unique stressors as a result. The stress experienced by frontline EMS personnel has been the focus of much international research (1-4). However, as dispatchers working in the EOC do not have direct physical contact with the public, this group is frequently overlooked and is under-researched. Without a clearer 
understanding of the unique experiences of EOC dispatchers, it is difficult to offer advice on how best to improve and promote wellbeing, and ultimately reduce sickness absence and staff turnover within this group. The present study aimed to address this by exploring the stress experienced by ambulance dispatchers at an EOC in the United Kingdom.

In the UK, emergencies are managed regionally by local EOCs. On receipt of an emergency (999) call, the incident is processed via an EOC, with one member of staff (a call operative) receiving the initial call, recording pertinent details on the nature of the patient's presenting complaint and triaging the call via a computer triaging system, such as NHS Pathways (5). This information is then passed to the dispatch team, who appropriately dispatch EMS resources as required. Prior research examining the stressors experienced by call operatives has been conducted in both the UK and internationally $(6,7,8)$, but to date the experiences of EOC dispatch personnel remain under-researched.

According to the most recent report from the UK Office for National Statistics, the national average sickness rate is $1.6 \%$ for men and $2.6 \%$ for women (9). Notably, the highest sickness absence rates in the public sector are workers in the healthcare sector: approximately $3.4 \%$ of healthcare sector worker days were lost to sickness in 2013 (10-12). Healthcare workers exhibit higher sickness absence rates than any other occupational groups (9), and often the reason given is stress, anxiety or depression. Thus, it is generally accepted that although healthcare work is rewarding, it can also be uniquely stressful.

Sickness absence in UK EMS staff however is more than twice the national average, reported at 6.78\% in the period between January and March 2014 (13). Indeed a recent report from the union UNISON who surveyed 1,332 NHS EMS workers in the UK, showed that 20\% of respondents reported a poor work-life balance, with a third taking time off in the past year due to stress (14). The causes of stress vary between healthcare roles, due to unique, role-specific stressors. For frontline emergency staff (e.g. paramedics and emergency medical technicians), some of the key contributors to stress include: exposure to traumatic scenes, having to take lifesaving action and the physical demands of manual handling. The effects of stress, if not well 
managed can lead to health issues in EMS personnel. The short- and long-term impacts of these stressors are well documented $(15,2,16,17)$. However, less is known about the experience of working in the 'back office' as an EOC call operative, and even less as an EMS dispatcher, and the lack of research in this area has been highlighted (14).

This study aimed to expand our understanding of the role of the EMS dispatcher, by taking a broad overview of the daily working experiences of dispatchers in one centre in an NHS setting, and the stressors encountered. We also explored how workers currently manage these stressors, and whether they feel their own strategies are effective at managing work-related stress.

\section{METHODS}

\section{Study Design}

Semi-structured qualitative interviews, analysed thematically.

\section{Selection of Participants}

Participants were recruited directly within the work environment, from a population of 36 permanent dispatch staff, working in one EOC in the south of England, UK. Purposeful sampling was used in order to represent a range of ages and years’ experience in the post (maximum variation sample (18). Nine participants (four female, five male) were recruited (quarter of the workforce population at this EOC). Participants were informed that the study was being conducted in order for the research team to gain an understanding about the experience of working in an EOC dispatch centre.

\section{Procedures}

Face-to-face interviews were conducted by the first author (AC), trained in qualitative research methods, with EMS dispatch personnel at one NHS EOC, in a quiet room away from the main control room. The interview schedule (Appendix 1) was developed by AC and the research team, based on consultation with the EOC manager, prior knowledge of EOC structure and with 
reference to existing literature. The EOC manager acted as a "key informant” (19) in identifying not only pertinent topics for discussion but also members of staff who could provide main points of variability for this research area. A final draft of the schedule was discussed with the practice manager in consultation with $\mathrm{AC}$ and $\mathrm{MC}$ prior to interviewing.

Questions within the schedule were open-ended, with various prompts provided to encourage participants to talk freely about their experiences of working in the EOC. Interviews lasted between 40-70 minutes each. The interviews consisted of two main sections: working in the EOC, and stress in this work setting. Interviews were recorded on a Dictaphone, and transcribed verbatim by AC. Any truncations were clearly marked, and explanations given for these, for example tangential discussion not related to the research question. Participants were given pseudonyms to retain confidentiality.

\section{Primary Data Analysis}

Thematic analysis, as defined by Braun \& Clarke (20), was identified as the most appropriate approach for these data, as it allowed a flexible, data-driven analysis, rather than one rooted to a specific theoretical framework. As prior research in this particular participant group is limited, this approach allowed for analysis to be primarily inductive, reflecting the lived experiences of participants. Thematic analysis also allows for a good overview and summary of a large body of data, as can be generated by a largely under-researched topic such as this, and generates what Braun \& Clarke refer to as "unexpected insights”. The analysis is informed, rather than being driven, by existing theory. Following Braun \& Clarke’s six-step method for theme development, each of the transcripts was read and analysed several times, and codes were cross-referenced between transcripts to provide an in-depth and holistic analysis. Similarities and contrasts between the individual interviews were noted. Initial codes were discussed with and cross-checked by a second researcher (MC). Themes were developed through a series of meetings between AC and MC, through a process of constant comparison and cross-referencing codes between transcripts. 


\section{Ethics}

This study was approved by the Faculty of Arts and Human Sciences Ethics Committee at the University of Surrey, UK, and the EMS Research and Development working group gave permission for access to staff.

\section{RESULTS}

\section{Characteristics of Study Subjects}

The sample ranged in age from 26 to 60 years, and all were white British. Participants had between 2-14 years' experience in the Emergency Operations Centre, and only two of the nine participants recruited had some background in medical training (as first aiders) prior to joining the EOC.

\section{Results}

Three key themes were developed, which include a number of related subthemes. The first main theme, (1) "How dispatch is perceived by others", includes two subthemes, (1a) "public perception” and (1b) “working with other teams”. The second main theme, (2) "What dispatch really involves”, includes two subthemes, (2a) “interpersonal issues” and (2b) “multitasking and prioritising”. Finally, the third main theme, (3) "Dealing with the stresses of dispatch" also includes three subthemes, these being (3a) "training, management and development”, $(3 b)$ "motivation and coping strategies”, and (3c) "post-shift recovery”.

\section{(1) How dispatch is perceived by others}

All of the participants mentioned feeling overlooked, misunderstood and marginalised. When specifically discussing the public perception (1a), participants described feeling invisible "...we are really the sort of the faceless sort of people" (Nick, male, 11 years in role)

“...nobody knows what we do.” (Fiona, female, 9 years in role) 
All participants recognised and accepted their role was one that the public were generally unaware of. However, what was more challenging for some participants was the lack of understanding from close friends and family. Most of the participants reported friends and family lacked understanding into what the role actually involved, or minimised the importance and pressure involved in the role -

“...that's what I find so difficult, they just have no concept of... what pressure we get put under...” (Paula, female, 7 years in role)

This difficulty Paula experienced when trying to discuss work matters with her husband led to such frustration that she stated she doesn't often look for support outside of work. Conversely, Clive felt able to gain some support from his wife by just having someone to talk to, and release tension -

“...I try to, I don't blow her away, but you have to, to be able to get on, because if you just store it up... it just gets worse and worse.” (Clive, male, 2 years in role)

All participants mentioned difficulties in their relationships with other teams involved with the EOC $(1 b)-$

"Your role in control is not seen as particularly attractive... you're almost like you're a necessity but you're enabling what's really important" (Sam, female, 7 years in role)

This hierarchy between roles is implicitly supported by the attitudes of dispatch staff “My next door neighbour was a paramedic, and for my whole childhood I basically worshipped him!" (Fiona, female, 9 years in role)

Participants suggested that their work is not valued as highly as other vital public service roles, despite the difficult nature of the work - 
“It's a tough job, it's a tough, tough job. It is, I mean I don't think we get enough money for what we do. I don't think anyone in this service gets enough money. When I look at what coppers are getting, as dispatchers we, you know I think we do as easily a vital job as police or fire." (Nick, male, 11 years in role)

Some participants identified poor inter-team communication as a source of personal stress, and were able to take proactive steps in improving relationships with other teams (by changing the way they spoke to ambulance crews, for example), thereby alleviating this source of strain -

"I basically treat people how I expect to be treated. Just with you know respect and a bit of courtesy. Same as I would do with anyone else. You can still do the job professionally, but you can still be kind to people.” (Nick, male, 11 years in role)

Sam took it one step further, but at a personal cost and time sacrificed, and she explicitly stated the one-sidedness of her efforts -

"I'd go out on the road and Third Man ${ }^{1}$ a lot and got to know some of the crews so that when they heard my voice they knew me. But as a dispatcher, why is that your responsibility? And it definitely wasn't my responsibility but it makes my day far easier. You know because they knew it was me, I'd quite like to think that now if they hear me on the radio they think... Yeah, and it's like you know I think when they know who you are they'll do a lot more for you [...] a lot of it was done in my own time, they do allow you to have two third-manning shifts a year, but that's getting quite difficult..." (Sam, female, 7 years in role)

Sam utilised what opportunities were available to her, to forge better working relationships and improve inter-team functioning. Another dispatch member Ron, benefited from having a “dual

\footnotetext{
${ }^{1}$ By "Third Man", Sam is referring to her being a third healthcare professional present in an ambulance crew; typically, ambulances operate with two healthcare staff. Third Manning is commonly used as a way of staff gaining experience of working on the frontline of emergency healthcare.
} 
role” that allowed him to split his working time between being a dispatcher, and also being an emergency medical technician -

“...you'd see so many crews that would get so frustrated, stuff happening, things come up on screen, go here do that, and they didn't know why. So it was just a nice link to have, as you know I have a background in the dispatch centre, even just spending 12 hours with someone in an ambulance, you can say to them "oh this is why they're doing that" or, suddenly it all makes sense. It just changes the whole... atmosphere, you know?” (Ron, male, 15 years in role)

Whilst Ron had the most direct links between the frontline staff and the EOC, all of the participants mentioned on some level or other a need for improving relationships between the teams.

Finally, one participant demonstrated an implicit lack of value for his own, current role “...once I've got my ECSW stuff over and done, that's when I'll start focussing on an access course to be a paramedic, so...[...] Yeah, out on the road. EOC is really a stepping stone.” (Terry, male, $6 \frac{1}{2}$ years in role)

Terry’s clear intentions to use EOC work as a way to access frontline emergency healthcare work, is initially shared by other participants (when they first joined the EMS) but after having experienced working in dispatch, they find they have an aptitude for it, enjoy it, and decide to stay

"I thought about going to the paramedic side, um but I just needed to get my foot in the door. So I started out in call taking, did that for about a year, and then the opportunity came up to do dispatch, so I went for it [...] Yeah. And I love it.” (Clive, male 2 years in role)

However, Terry has been working in the EOC for two years now, and still sees working as a paramedic to be the "gold standard”, and EOC as a "stepping stone”. 


\section{(2) What dispatch really involves}

Although the majority of interviews focussed on negative experiences such as stressors and inter-personal conflict, it is important to note that many of the participants identified positive aspects of their work which they valued -

"I can honestly say I go home at the end of every single day and I've made a difference to at least one person [...] Not many people get that kind of satisfaction” (Sam, female, 7 years in role)

“Ultimately you... you're potentially saving lives. [...] Getting the crews out to patients, so that's kind of the, the reward." (Clive, male, 2 years in role)

“When you do achieve, like when someone's in cardiac arrest and you've got the crew there in good time and they're there in four minutes and lots of times we've got the person back and they make a recovery, I've had a couple of letters, where what I've done has made a difference to people.” (Paula, female, 7 years in role)

However, a broad range of issues were also identified, and these form the main focus of the study. When discussing the day to day stressors involved in dispatch work (2), a lack of resources was mentioned -

"In dispatch, the main stressors are not having the resources, in terms of ambulances for emergencies.” (Jane, female, 13 1/2 years in role)

All participants mentioned interpersonal issues (2a) as a significant source of stress. Without positive working relationships between dispatch and other teams, stress is never resolved but simply deflected from one team onto another. Several participants reported negative treatment at the hands of paramedic crews - 
“...everyone says we're like a buffer, or um the crews, who are they gonna talk to? That's no excuse. If I have stress, I don't get, I'm not snapping at a crew am I? And barking orders at them because I'm upset about something. It doesn't work like that.” (Nick, male, 11 years in role)

Participants reported that the dispatch role involves a great deal of multitasking and prioritising (2b). Nick neatly summed up some of the additional work pressures that dispatchers come under “...when we're dispatching, you've got four screens, you've got your foot on a pedal, like a clutch on a car, you're talking to crews, listening to everything going on around you, alright people maybe say to you, tell this crew don't go here, don't go there, they've got a weapon, violent, leave it to the police or whatever, uh you might have a crew call up from the radio, asking what's going on just want to pass the time at the hospital, you could have other jobs coming in, so when you're dispatching sometimes you could be doing about half a dozen things at once? No I really mean that, literally half a dozen things at once. And they're all important." (Nick, male, 11 years in role)

Staff members are allotted a certain amount of time per shift in which to take breaks, but how they choose to take these breaks throughout their shift is relatively flexible. Whilst a break from their desk may award them time to relax and recover from some of the stresses experienced whilst on shift, they reported that returning to their desk can mean returning to a completely different state of affairs than when they left. Trying to get back “in step” after a break can be stressful, and as such many dispatchers choose not to fully utilise their breaks, with some not leaving their desk at all during their 12-hour shift, except to use the toilet.

"...we do find that if you took that break, you remove yourself from what is going on. In some ways it's more of a hindrance." (Darren, male, 13 years in role) 
“It's much harder to stand up, walk out, and take a break. It's not impossible and it's not something you can't do, because nobody gets, nobody makes it hard for you to do it... You make it hard for yourself." (Paula, female, 7 years in role)

Darren agreed in part with this, but in the same sentence attributed some of the blame to the structure of the EOC -

“I don't think we manage our breaks well. I certainly don't. Part of that's just me, part of that's not really having the structure for that." (Darren, male, 13 years in role)

\section{(3) Dealing with the stresses of dispatch}

All participants were able to identify positive strategies for dealing with the stresses of dispatch (3), including appropriate training, management and development ( $3 a)$. Good training helps staff feel competent, and gives them a sense of responsibility over their own performance. Conversely, inappropriate or inadequate training not only leads to poor performance, but staff are less likely to take responsibility for their own actions -

“...if you train people properly, they're more likely to take responsibility for their own actions. If you... part of me thinks, if I take a call, I see some people who train who just don't seem to have a clue... you know, if I mess up on a call, and they say, well you messed up, I'd just say well I just did what I was told, you know, that's what they told me...” (Jane, female, 13 1/2 years in role)

Jane suggested that appropriate training not only improves performance, but makes staff feel valued, improves job satisfaction, and overall improves staff wellbeing “...you're investing in them. They feel cared about. They think, oh you're taking care of me, I've got what I need, I've got everything I need, I've got the full package. I'm a professional." (Jane, female, 13 1/2 years in role) 
Several participants noted a dissatisfaction with the current training provided to dispatch staff, stating that initial training left new-starters feeling unprepared and overwhelmed, and in some instances this can have serious consequences for patient care -

“... it's just they've not got much life experience and actually sometimes that can make some quite grave errors because they have no understanding of someone in excruciating pain for example and the crew are shouting for a paramedic, it just goes over his head...he's learning, but what a baptism of fire.” (Sam, female, 7 years in role)

Staff do receive regular training days at present, and these are multi-disciplinary (involving call operatives, dispatchers and ambulance crews) so in theory they are an effective team building exercise. However, several participants felt the subject matter covered in these sessions was not relevant to all the teams involved, and some members of staff were left feeling as though their time was being ill-spent -

"We are given more training, I do think the training is a bit lacking..." (Darren, male, 13 years in role)

The majority of participants also demonstrated a number of adaptive coping strategies and protective factors $(3 b)$, including personal motivations and benefit finding. One of the most interesting methods of coping came from Jane, who suggested a level of emotional detachment, and demarcating work- and home-life as key -

“...sometimes you have to. To protect yourself. Yeah, you do. Otherwise you'd go insane. You can't take it home with you. But it's about finding a balance." (Jane, female, 13 1/2 years in role)

Clive sees home- and work-time as clearly distinct, and this allows him to cope with stressful events of the day, and exercise good post-shift recovery (3c) -

“... when I'm here, I'm on work time. I try not to let things get to me, but... When I get home, I don't want to think about it. Get it out the way." (Clive, male, 2 years in role) 
Darren however does not seem to have such a clear cut approach to his post-shift unwinding, and almost begrudged the time it takes him to leave work behind -

“...if I told you about last night... absolutely.... I went home, I sat out... I put out like a deckchair, I got a cup of tea and I sat, little bit of music, and I sat on my own there for an hour. That's an hour - gone. Just to unwind." (Darren, male, 13 years in role)

Initially when asking Darren what his routine was after finishing work, he confessed to not really having a routine. As Darren explained, he often returns to work not feeling refreshed, and he now does not experience the same enjoyment in his role as he used to.

The pressures of the role are great, but were they unmanageable, there would not be a core of committed staff who had stayed with the Trust for ten years or more -

“...it's a maintained stress. And that's just a case of if you can take that, you'll enjoy the job." (Nick, lines 70-1)

\section{DISCUSSION}

The majority of the dispatch staff interviewed for this study stated that they enjoy and take pride in their work, despite the stressors they identified: the rewards of the role make the stressors bearable, at least for the longer-serving members of dispatch staff. However, the participants expressed different degrees of demoralisation: even the most resilient of staff stated that at some points they find the pressures of their role, combined with a lack of appropriate support or recovery time, overwhelms any intrinsic motivation for the job. Participants identified a lack of resources (i.e. ambulances), increasing call-volume, interpersonal difficulties (within their team, and between their team and others) and lack of recognition as the main sources of stress within their role.

In line with theoretical concepts outlined by Fletcher \& Payne (21), the present study has identified a number of extra- and intra-personal stressors, falling into three broad categories: resources and pay, interpersonal difficulties, and feeling overworked and undervalued. Without 
effective management or sufficient post-shift recovery, sustained stress can lead to allostatic load (22) and long-term negative changes in staff self-perception and ability to perform their job effectively. Allostatic load refers to 'the wear and tear on the body' which grows over time when the individual is exposed to repeated stress, eventually leading to ill-health (22). Over time this can result in increased levels of sickness absence (performance figures suggest this is already happening) as well as burnout in staff, and higher rates of staff attrition. One of the participants interviewed displayed classic early signs of job burnout, such as cynicism towards work, feelings of fatigue and irritability, and feelings of unhappiness both about their work and themselves (2325). The cumulative effect of this on-going stress, added to the lack of higher management support and recognition, can lead to feelings of helplessness, low self-worth, and apathy - all signs of potential burnout (25). There are a few obvious but improbable solutions, such as hiring more staff to deal with the volume of calls, or providing more ambulances to meet demand. Whilst this might provide some support/relief in the short-term, it does not guarantee improved long-term psychological wellbeing.

\section{Stress-management strategies suggested by participants}

The dispatch personnel interviewed for this study identified a number of positive changes they themselves have made in order to manage the pressures of their work, to varying degrees of success. One of these, interacting positively with others teams in order to forge better working relationships, is a simple but effective strategy to deal with the daily pressures of the job. Whilst it is impossible to determine — within the current data — to what extent this relationship building has on job satisfaction and sickness rates, previous research suggests that this is an idea worth pursuing. García-Izquierdo \& Ríos-Rísquez (26) identified interpersonal conflicts as a key component of burnout in workers in emergency departments, and Apker, Propp, Zabava Ford, \& Hofmeister (27) suggest that effective, positive communication can promote effective team working and in turn improve morale. Rather than relying on staff initiative and giving up leisuretime (thus blurring the lines between work and leisure), these findings suggest that a simple 
initiative, promoting cross-team cohesion, could help improve job satisfaction not only in dispatch staff, but across emergency operations as a whole. This could include regular inter-team shadowing (such as dispatchers 'third manning' on ambulance crews, but also paramedics and EMTs crews coming in to the Emergency Operations Centre on positive grounds to observe and assist EOC staff), and regular multi-disciplinary team training days, focussing on positive, effective communication, and stress-awareness. By emphasising the importance of larger-team cohesion, EOC staff and ambulance crews will be able to see the value and importance not only in each other's roles, but also value the functioning of the larger team as a functioning system, rather than isolated groups.

As mentioned by the participants in this study, appropriate training is an important part of investing in an organisation’s staff. By giving staff appropriate training (with regular updates, opportunities for self-improvement, or even qualifications), staff feel valued and confident, and this can increase effective working. An effective use of this training time could be improving inter-team communications and boost morale through team building exercises. Team building exercises have been shown to improve communication skills and boost productivity (28-30). By having shared, enjoyable problem-solving experiences, teams are able to bond socially and form positive interdependency, rather than being isolated groups.

The participants interviewed in the present study demonstrate a broad range of skills and experience, and likewise a spectrum of different degrees of coping with the effects of stress. Participants identified the importance of 'finding a balance' which is particularly interesting considering existing homeostatic and allostatic models of psychological wellbeing $(21,22)$. Clearly dispatch staff cannot control how the events of a shift will unfold, but they can, to some extent regulate how they react to those events. This does not mean that staff need to disengage completely from the emotional element of the work they do, but that a level of detachment needs to be achieved in order for staff to safeguard their own wellbeing, and protect against emotional exhaustion (31,32). A key example of poor post-work recovery was given by Darren, who stated that he does not feel refreshed after "unwinding” from work: he may not have been unwinding at 
all, but engaging in what is referred to as “work-related affective rumination” $(33,34)$, which involves dwelling on events from his shift, but remaining in a state of heightened emotional arousal. Without appropriate and effective recovery, staff become fatigued, return to work unrested, which can lead to ineffective working and a lower threshold for job strain. This in turn results in what Fletcher \& Payne refer to as "secondary intra-person stress”: whereas the daily pressures of the role may be tolerable or manageable in normal circumstances, because the staff member is approaching their usual shift whilst feeling fatigued, they are unable to work effectively and their workload becomes unmanageable (21). Had the worker been able to recover from their previous shift, they would return to their next shift refreshed, and the same workload would be manageable, without secondary intra-person stress ever becoming an issue.

Healthcare staff are particularly at risk of allostatic load and subsequent emotional exhaustion $(1,25,35)$, and this may be due in part to the nature of their role: their role is essentially a caring role which is patient centred, and this involves a degree of emotional involvement, even for dispatchers who are not patient-facing. Part of that balance and self-preservation is found in appropriate opportunities and strategies for recovering from stressful events ("shutting off allostatic activity after stress”, (22)). There is a real need and importance for staff to get adequate time after their shifts to recover, both mentally and physically. Inadequate recovery after work has been associated with poor health outcomes $(22,33,36)$, and the negative effects of poor recovery can be cumulative. One key predictor of poor recovery is an inability to demarcate work- and home-life appropriately.

Another simple, effective and essentially cost-neutral method of demonstrating to staff that they are valued is by recognising individual achievements. This could be something as little as having a staff email once a week identifying one incident in which a particular member of staff or team demonstrated skill and competence, or a personal email or letter to members of staff to thank them for their hard work, to show gratitude and appreciation of what the staff member is doing well (37). 
This study identified that the primary reason dispatch personnel stay in their role long-term is they feel the work they do is important and meaningful. This self-held view is not reflected in how they feel they are treated by out-group members. On the whole, dispatch personnel feel as though the importance of their work is currently not recognised by the general public, valued by other teams that work alongside them, or by higher management, in the same way that frontline medical staff are. Participants felt overlooked, misunderstood and marginalised, not only regarding public perception, but also from co-workers in other teams, such as call operatives and ambulance crews. Whilst from a different area of the emergency services and observed in participants from a different country, this feeling of being a "second-class citizen” was also observed by Burke (38) is his research into stress experienced by police dispatchers. Similar to Burke’s dispatchers, there is a disparity between the amount of pressure the dispatch staff are under, and the respect and recognition it affords them.

Poor interpersonal relationships between dispatch and crews are not helped by a lack of structure to promote team-building between the two departments. As mentioned by participants, dispatchers are allowed two shifts "on the road” per year, but these are often difficult to orchestrate due to staff shortages. There is no similar arrangement in the opposite direction: paramedics are given a visit to the EOC as part of their initial training, but not actively encouraged to gain any working experience on the ground with the dispatch team or call operatives. It is clear from many of the participants that improving communications and perceptions between dispatch and other teams can lead to a reduction in work-related stress, not only in their own team, but other teams as well.

By changing how dispatch personnel are perceived, treated, and their work recognised will lead to staff to feel valued, they will experience greater job satisfaction, and ultimately perform their duties more effectively. In the longer term this could lead to reduced levels of sickness absence and a reduction in the number of ambulance dispatch personnel intending to leave.

\section{LIMITATIONS}


Inevitably, there is a degree of subjectivity involved in the type of analysis used for this study, and this is complicated further by the fact that the interviews were conducted and coded by a sole researcher, and therefore a single perspective. However, it has been previously suggested that using a single researcher to conduct and code the full set of interviews is in fact an advantage, as they will be fully immersed in the data and have a unique relationship with the participants involved $(39,40)$. In the interests of rigour and validity $(41)$, the initial set of codes was cross-checked by AC in discussion with MC and subsequent themes developed from these. Moreover, as research in the area of stress in dispatch staff is limited, and the lead researcher had limited prior experience within an EOC setting, the researcher was able to approach the data with an open and relatively unbiased perspective. Efforts were also made to compare findings with existing research findings in related, similar settings, such as call-centre work, NHS 111, police and fire dispatch operations, and other areas of emergency healthcare, both in the UK and internationally.

Whilst participants were recruited to purposefully reflect a range of ages, years’ experience, and breadth of opinion, the findings from this study only reflect the collective views of dispatchers working at one EOC within one NHS Trust. It is possible that the issues identified in this study are particular to the centre from which participants were recruited, and only by recreating this study at other EOC and other NHS Trusts could this possibility be discounted. The findings of this study however, may be transferable to other, similar settings, and this study does present similarities with existing research in similar settings. As further research emerges, it may be possible to make increasing generalisations across EOCs, both in the UK and internationally.

\section{CONCLUSION}

EOC dispatch personnel take pride in their work and find the job rewarding but many staff members also feel overloaded, stressed, and undervalued by others. The study findings suggest that there needs to be greater education and positive interpersonal interaction between dispatch staff and other teams, more opportunity for dispatchers to improve existing skills, regular management supervision and support. Staff would also benefit from training in order to build on existing coping 
strategies to promote post-shift recovery. With EOC staff sickness absence currently alarmingly

high compared to national averages, all avenues to improve this should be considered.

\section{References}

1. Adriaenssens J, de Gucht V, Maes S. The impact of traumatic events on emergency room nurses: findings from a questionnaire survey. Int J Nurs Stud. Elsevier Ltd; 2012;49(11):1411-22.

2. Hegg-Deloye S, Brassard P, Jauvin N, Prairie J, Larouche D, Poirier P, et al. Current state of knowledge of post-traumatic stress, sleeping problems, obesity and cardiovascular disease in paramedics. Emerg Med J. 2013;242-7.

3. Adriaenssens J, De Gucht V, Maes S. Determinants and prevalence of burnout in emergency nurses: a systematic review of 25 years of research. Int J Nurs Stud. Elsevier; 2014;52(2):649-61.

4. Salminen-tuomaala M, Leikkola P, Paavilainen E. Emergency health care professionals' experiences of factors that influence care quality and safety. Clin Nurs Stud. 2015;3(3)

5. NHS Pathways - NHS Connecting for Health [Internet]. Advanced Health \& Care. 2011. Available from:

http://www.connectingforhealth.nhs.uk/systemsandservices/pathways

6. Turnbull J, Pope C, Rowsell A, Prichard J, Halford S, Jones J, et al. The work, workforce, technology and organisational implications of the " 111 " single point of access telephone number for urgent (non-emergency) care: a mixed-methods case study. Heal Serv Deliv Res. 2014;2(3):1-140.

7. Forslund K, Kihlgren a., Kihlgren M. Operators’ experiences of emergency calls. J Telemed Telecare. 2004;10(5):290-7.

8. Forslund K, Kihlgren M, Sorlie V. Experiences of adding nurses to increase medical competence at an emergency medical dispatch centre. Accid Emerg Nurs. 2006;14(4):230-6.

9. Office for National Statistics. Full Report : Sickness Absence in the Labour Market, February 2014.

10. Johansen ML. Conflicting priorities: emergency nurses perceived disconnect between patient satisfaction and the delivery of quality patient care. J Emerg Nurs. Emergency 
Nurses Association; 2014;40(1):13-9.

11. Lu H, Barriball KL, Zhang X, While AE. Job satisfaction among hospital nurses revisited: a systematic review. Int J Nurs Stud. Elsevier Ltd; 2012;49(8):1017-38.

12. Richards D a, Bee P, Barkham M, Gilbody SM, Cahill J, Glanville J. The prevalence of nursing staff stress on adult acute psychiatric in-patient wards. A systematic review. Soc Psychiatry Psychiatr Epidemiol. 2006;41(1):34-43.

13. Health \& Social Care Information Centre. NHS Sickness Absence Rates [Internet]. 2014. Available from: http://www.hscic.gov.uk/catalogue/PUB14544/sick-abs-ratejan-mar-2014-rep.pdf

14. UNISON. Stress epidemic stretches ambulance service to breaking point [Internet]. 2014. Available from: http://www.unison.org.uk/news/stress-epidemic-stretchesambulance-service-to-breaking-point

15. Beaton RD, Murphy SA, Pike KC, Corneil W. Social Support and Network Conflict in Firefighters and Paramedics1. West J Nurs Res. 1997;19(3):297-313.

16. Leblanc VR, Regehr C, Tavares W, Scott AK, Macdonald R, King K. The impact of stress on paramedic performance during simulated critical events. Prehosp Disaster Med. 2012;27(4):369-74.

17. Sofianopoulos S, Williams B, Archer F. Paramedics and the effects of shift work on sleep: a literature review. Emerg Med J. 2012;29(2):152-5.

18. Marshall MN. Sampling for qualitative research. Fam Pract. 1996;13(6):522-5.

19. Gilchrist VJ, Williams RL. Key Informant Interviews. Doing Qualitative Research Volume 4. 1999. p. 71-88.

20. Braun V, Clarke V. Using thematic analysis in psychology. Qual Res Psychol. 2006;3:77-101.

21. Payne R, Fletcher B. Stress At Work: A Review and Theoretical Framework, II. Pers Rev. 1980.

22. McEwen BS. Stress, adaptation, and disease. Allostasis and allostatic load. Ann N Y Acad Sci. 1998;840:33-44. 
23. Gokcen C, Zengin S, Oktay M, Alpak G, Al B, Yildirim C. Burnout, job satisfaction and depression in the healthcare personnel who work in the emergency department. Anatol J Psychiatry. 2013;1.

24. Malakh-Pines A, Aronson E, Kafry D. Burnout: from tedium to personal growth. Free Press; 1981.

25. Weibel L, Gabrion I, Aussedat M, Kreutz G. Work-related stress in an emergency medical dispatch center. Ann Emerg Med. 2003;41(4):500-6.

26. García-Izquierdo M, Ríos-Rísquez MI. The relationship between psychosocial job stress and burnout in emergency departments: an exploratory study. Nurs Outlook. 2012;60(5):322-9.

27. Apker J, Propp KM, Zabava Ford WS, Hofmeister N. Collaboration, credibility, compassion, and coordination: professional nurse communication skill sets in health care team interactions. J Prof Nurs. 2006;22(3):180-9.

28. Klein C, DiazGranados D, Salas E, Le H, Burke CS, Lyons R, et al. Does Team Building Work? Small Group Research. 2009. p. 181-222.

29. Salas E, Rozell D, Mullen B, Driskell JE. The Effect of Team Building on Performance: An Integration. Small Group Research. 1999. p. 309-29.

30. Tannenbaum SI, Beard RL, Salas E. Chapter 5 Team Building and its Influence on Team Effectiveness: an Examination of Conceptual and Empirical Developments.

31. Rod M, Ashill NJ. The impact of call centre stressors on inbound and outbound callcentre agent burnout. Manag Serv Qual. 2013;23(3):245-64.

32. Wittmer JLS, Martin JE. Emotional Exhaustion Among Employees Without Social or Client Contact: The Key Role of Nonstandard Work Schedules. J Bus Psychol. 2010;25(4):607-23.

33. Cropley M, Zijlstra F. Work and rumination. Handb Stress Occup. 2011;(1776):1-29.

34. Querstret D, Cropley M. Exploring the relationship between work-related rumination, sleep quality and work-related fatigue. J Occup Health Psychol. 2012;17(3):341-53.

35. Halpern J, Maunder RG, Schwartz B, Gurevich M. Identifying, describing, and expressing emotions after critical incidents in paramedics. J Trauma Stress. 2012;25(1):111-4. 
36. Cropley M, Millward L. How do individuals "switch-off” from work during leisure? A qualitative description of the unwinding process in high and low ruminators. Leis Stud. 2009;28(3):333-47.

37. Currid T. Experiences of stress among nurses. Nurs Stand. 2009;23(44):40-6.

38. Burke TW. Dispatcher stress. In: Umeh DC, editor. Protect Your Life!: A Health Handbook for Law Enforcement Professionals. Looseleaf Law Publication; 1999. p. 79-86.

39. Bradley EH, Curry L a, Devers KJ. Qualitative data analysis for health services research: developing taxonomy, themes, and theory. Health Serv Res.

2007;42(4):1758-72. t

40. Morse JM, Richards L. README FIRST for a User's Guide to Qualitative Methods. SAGE Publications; 2002.

41. Yardley L. Dilemmas in qualitative health research. Psychol Heal. 2000;15:215-28. 